\title{
EXPERIÊNCIA DE CAMPO NECESSÁRIA À FORMAÇÃO DO(A) ENFERMEIRO(A)
}

\author{
Clara Wolfovitch * \\ Floripes Cavalcante Farias * \\ Gilka Conceição Xavier da Silva * \\ Josicélia Dumet Fernandes * \\ Marline Galvão de Souza *
}

RBEn/03

WOLFOVITCH, C., e colaboradores - Experiência de campo necessáría à formação do(a) enfermeiro(a). Rev. Bras. Enf., Rio de Janeiro, 28 : 26-55, 1975.

\section{INTRODUÇÃO}

O ensino da Enfermagem vem sofrendo, nesta última década, modificações crescentes, influenciado por fatores de ordem econômica, social e cultural que se efetuam na sociedade brasileira.

O planejamento desse ensino deve estar orientado para as reais necessidades do país e, quando bem realizado, é fator decisivo na formação profissional Os professores de enfermagem têm-se preocupado com o assunto, porque, por uma necessidade social, o enfermeiro recém-graduado inicia a vida profissional ocupando cargos de chefia, sem preparo específico além daquele obtido no curso de graduação. importante traçar-se uma equivalência entre o programa educacional e o comportamento do produto.

Com a nova formulação do currículo mínimo para os cursos de enfermagem, de carga horária de $2.500 \mathrm{hs,} \mathrm{tornou-se}$ necessário um estudo para distribuição das disciplinas, sobretudo daquelas que necessitam de campo de estágio: sem interferir, todavia, na qualidade do ensino e na formação do enfermeiro.

As transformações que se processam na realidade brasileira exigem que 0 preparo do enfermeiro seja analisado e adequado para uma participação ativa na estrutura social.

O trabalho exercido em planejamento: supervisão, controle e avaliação das atividades de enfermagem nas instituições de saúde reflete-se no nível de saúde da comunidade, constituindo-se por isto uma exigência social.

Um dos grandes problemas no exercicio da profissão do enfermeiro, relaciona-se com as atividades administrativas de unidades de enfermagem. Entende-se

* Professora da Escola de Enfermagem da Universidade Federal da Bahia. 
WOLFOVITCH, C., e colaboradores - Experiência de campo necessária à formação do(a) enfermeiro(a). Rev. Bras. Enf., Rio de Janeiro, 28 : 26-55, 1975.

como função administrativa aquela relacionada com a liderança da equipe de enfermagem, em que o enfermeiro trabalha no sentido de prover condições para o bom atendimento do paciente, não significando, portanto, desempenho de trabalhos burocráticos, em detrimento da assistência direta. O trabalho burocrático deveria ser feito por outros profissionais que estão sendo introduzidos na equipe de enfermagem, com praparo de nível médio. Também devido ao grande número de pacientes que os enfermeiros têm sob sua responsabilidade, torna-se difícil prestar a assistência integral ao paciente.

O aparecimento de novos profissionais para desempenharem |tarefas de acordo com o preparo facilita o trabalho em equipe. O enfermeiro, como líder da equipe de enfermagem, coordena serviços de enfermagem, presta assistência direta ao paciente, desenvolve a atividade de ensino e supervisão, prepara pessoal, educa indivíduos e grupos da comunidade, como também participa da equipe que introduz os aspectos de saúde nos currículos das escolas primárias e secundárias. Admite-se que o preparo atual recebido pelo enfermeiro qualifica-o para as atividades supra citadas.

Em relação à função assistencial, específica do enfermeiro, este não se limita apenas a executar a prescrição médica, mas sim, a planejar a assistência de acordo com o doente, afeç̧ão e tratamento.

Todavia, a assistência direta de enfermagem é ministrada na sua maioria pelos auxiliares e atendentes. Essa ausência do enfermeiro na assistência direta ao paciente é sentida pela comunidade, pelos profissionais a fins e pelo próprio enfermeiro. Daí a necessidade de se estabelecer áreas de ação prioritárias, selecionando-se atividades exclu- sivas no enfermeiro, tais como: identificar e analisar as necessidades de enfermagem do paciente e planejar a assistência de enfermagem; ao delegar atividades que podem ser desempenhadas por outros membros da equipe, o enfermeiro deve assumir a responsabilidade daqueles cuidados que somente ele deva executar.

\section{OBJETIVOS}

O presente trabalho pretende:

1. Estudar as principais funções e atividades do enfermeiro na área hospitalar, de saúde pública e de ensino;

2. Avaliar o preparo do enfermeiro em relação ao trabalho que exerce;

3. Sugerir o preparo do estudante de acordo com o real trabalho desenvolvido pelo enfermeiro.

\section{DIAGNÓSTICO DA SITUAÇAOO FUNCIONAL DO ENFERMEIRO EM SALVADOR}

\section{NOTA METODOLÓGICA}

Para a elaboração do presente diagnóstico realizou-se um levantamento entre os enfermeiros atuantes, a fim de sugerir, com maior objetividade, a experiência de campo mais conveniente à formação do enfermeiro.

Traçados os objetivos, o estudo foi distribuido nas seguintes estapas:

1.1. Levantamento bibliográfico.

1.2. Elaboração do questionário.

1.3. Dimensionamento da amostra

1.4. Trabalho de campo.

1.5. Tabulação.

1.6. Análise.

Tomaram-se como universo os enfermeiros da Cidade do Salvador, nas diversas áreas de atuação. O levantamento preliminar identificou 297 enfermeiros e, sobre este total, calculou-se uma amostra estratificada, tomando como 
WOLFOVITCH, C., e colaboradores - Experiência de campo necessária à formaçáo do(a) enfermeiro(a). Rev. Bras. Enf., Rio de Janeiro, $28: 26-55,1975$.

base para a estratificação as áreas de atuação, chegando-se a uma amostra de 165 enfermeiros a serem entrevistados, distribuídos nos estratos da seguinte maneira: 107 hospital; 31 Saúde Pública e 27 ensino. Para o cálculo da estratificação foi utilizada a repartição ótima de Neyman.

Utilizaram-se além do questionário, dados secundários provenientes dos arquivos da Escola de Enfermagem da Universidade Federal da Bahia, com a finalidade de adquirir elementos retrospectivos sobre a distribuição da carga horária das disciplinas, numa série consecutiva de 10 anos. (Anexo I)

\section{ANALISE DOS DADOS}

$\mathrm{Na}$ cidade de Salvador, $41,2 \%$ dos enfermeiros ocupam cargo de chefia de unidade; $16,4 \%$ estão dedicados ao ensino e os restantes se distribuem por ordem de significação nos seguintes cargos: chefia de serviço, assistência, chefia de setor e outros cargos (Anexo II).

Quanto ao local de trabalho, 64,9\% estão na área hospitalar, desempenhando as funções de chefia de unidades de enfermagem, assistência e chefia de serviços.

Esta situação configurada, pode dar a idéia de um enquadramento do enfermeiro em suas funções específicas. Entretanto, a análise do conteúdo da ocupação revela que as atividades desempenhadas estão longe de corresponder ao título que se lhe atribui. O conteúdo da função varia, desde as tarefas consideradas fundamentais à profissão, àquelas completamente inadequadas. Daquelas atividades, expressa pelos enfermeiros chefes de serviço como sendo suas atribuições, apenas $29,0 \%$ foram consideradas como sendo específicas do cargo que ocupam. (Anexo III)

As atividades do enfermeiro na che- fia de setor ou em saúde pública apresentam um grau de definição e especificidade considerável; $70,0 \%$ dos enfermeiros pesquisados estavam mais ou menos enquadrados dentro das atividades específicas do seu cargo, sendo esta função a que apresenta menor desvio entre as analisadas.

Parece haver uma relação entre este ajustamento e a natureza do trabalho em si, devido à possibilidade da enfermagem planejar e executar as atividades em equipe, onde o fenômeno interdisciplinar funciona como conjunto e não como um elemento de mutilação.

Como chefes de unidades de enfermagem os enfermeiros exercem suas atividades mais ou menos dentro do padrão esperado, atingindo um percentual de $50,0 \%$. Entretanto, existe um volume bastante significativo de atividades que fogem à sua função.

Em relação à assistência, que se admite ser a função específica do enfermeiro, apenas $13,3 \%$ desempenham esta função. Destes, $95,4 \%$ estão em hospital e 4,6\% em ambulatórios.

Entretanto, acrescente-se que os enfermeiros responsáveis pela chefia de unidades de enfermagem incluem nas suas atividades a assistência ao paciente.

Quanto ao tipo de hospital, $38,2 \%$ dos enfermeiros pesquisados trabalham em hospital geral, 33,3\% em hospital especializado e $28,5 \%$ não trabalham em hospital. Os que trabalham em hospital geral distribuem-se por ordem de significação nos seguintes cargos ou funções: chefia de unidades de enfermagem, assistência, ensino, chefia de serviço e chefía de setor; também por ordem de significação, os que trabalham em hospital especializado distribuem-se na seguinte ordem: chefia de unidade de enfermagem, chefia de serviço, assistência e chefia de setor (Anexo IV). 
WOLFOVITCH, C., e colaboradores - Experiência de campo necessária à formação do(a) enfermeiro(a). Rev. Bras. Enf., Rio de Janeiro, $28: 26-55,1975$.

Tomando como b o cargo ou função, observa-se que apenas os graduados em Enfermagem Geral e em Enfermagem de Saúde Pública ocupam cargo de chefia de serviço. No cômputo geral os cargos de chefia são desempenhados predominantemente pelos graduados apenas em Enfermagem Geral (Anexo V).

O tempo de exercício na função varia de menos de um ano a mais de vinte anos sendo que $38,5 \%$ dos chefes do serviço têm menos de um ano, 26,9 têm de um a menos de cinco anos, diminuindo consideravelmente a incidência nas faixas seguintes até atingir o limite, sendo que não existem, em chefia de serviço, enfermeiros com mas de vinte anos na função. A maior estabilidade de pessoal concentra-se em assistência e ensino (Anexo VI).

O exercício do cargo ou função não supõe necessariamente experiência anterior à admissão no atual emprego visto que $29,7 \%$ dos enfermeiros pesquisados não a tinham; essa incidência é mais relevante no caso dos chefes de unidade de enfermagem, pois, $44,1 \%$ ocupam o cargo sem nenhuma experiência anterior. Entre os chefes de serviço, 30,8\% tinham experiência anterior na função, $15,4 \%$ a tinham em chefia de setor e $30,8 \%$ em chefia de unidade de enfermagem. Quanto à chefia de setor $17,6 \%$ tinham experiência anterior na função. Chama-se a atenção, entretanto, para o caso da assistência, pois $40,9 \%$ dos enfermeiros hoje nesta função já chefiaram unidade de enfermagem. Dos enfermeiros vinculados ao ensino, apenas $11,1 \%$ tinham experiência anterior na função. Os demais vieram das seguintes áreas: chefia de unidade de enfermagem, chefia de serviço, assistência e chefia de setor. Observa-se que $59,2 \%$ dos enfermeiros com função de ensino saíram de cargos de chefia. Focalizando isoladamente a assistência como uma fonte de experiência, observa-se que essa não constitui a fonte básica.

Relacionando o tempo de função observa-se que $20,0 \%$ dos enfermeiros têm menos de um ano de trabalho e que destes, $30,3 \%$ exercem o cargo de chefia de serviço; $39,3 \%$ exercem função de chefia de unidade de enfermagem, verificando-se, portanto, que logo após o término do curso vão ocupar cargos de chefia, afirmação corroborada com a incidência de $60,7 \%$ dos enfermeiros em exercício que têm menos de cinco anos de função. Observa-se por outro lado que $29,7 \%$ dos enfermeiros não exerceram cargos anteriores, chamando a atenção a incidência no caso de chefia de unidade de enfermagem, pois, $44,1 \%$ dos que exercem o cargo de chefia nunca exerceram cargos anteriores. Além disso, convém chamar a atenção para o fato de que a experiência anterior quase nunca é no campo de assistência mas já em outros campos de chefia.

Enfatizando melhor a assistência relacionada com os diversos cargos, quase que a totalidade dos enfermeiros que hoje trabalham em chefia, nunca trabalharam em assistência. Dos vinculados ao ensino, a maior incidência da experiência anterior é em chefia de unidade. Embora não se queira explicar o desvio de função, pretende-se mostrar, apenas, que não existe pré-condições, estágios probatórios ou qualquer mecanismo que prepare para o exercício das funções de chefia, ficando os recémgraduados expostos aos vícios e defeitos anteriores e impossibilitados de anular ou mesmo minimizar estes defeitos devido à falta de preparo específico e experiência (Anexo VII).

Analisando as áreas de graduação observa-se que $69,1 \%$ dos enfermeiros são graduados em enfermagem geral, aj se concentrando a maioria das chefias. 
WOLFOVITCH, C., e colaborad’res - Experiência đe campo necessária à formação do(a) enfermeiro(a). Rev. Bras. Enf., Rio de Janeiro, $28: 26-55,1975$.

$\mathrm{Na}$ área da enfermagem obstétrica são especializadas apenas $13,3 \%$ e $17,6 \%$ na de enfermagem de saúde pública. Chamamos a atenção para o seguinte: à exceção de chefia de serviço, todas as outras funções são exercidas indistintamente (Anexo V).

Apenas $32,1 \%$ fizeram curso de Enfermagem Obstétrica e de Saúde Pública e, destes, $50,0 \%$ estão em cargo de assistência, $15,4 \%$ em chefia de serviço e os demais se distribuem mais ou menos equitativamente pelos outros cargos ou funções. Portanto, $67,9 \%$ dos enfermeiros em atividade na cidade de Salvador, não cursaram aqueles estudos e, destes, $84,6 \%$ ocupam cargo de chefia de serviço, $67,7 \%$ estão no ensino, $66,2 \%$ em chefia de unidades de enfermagem e $64,7 \%$ em chefia de setor (Anexo VIII).

Observa-se, pois, a grande incidência de enfermeiros desempenhando o cargo de chefia, sem preparo específico para o mesmo, sem curso de pós-graduação, utilizando apenas os conhecimentos básicos do curso profissionalizante. Portanto, a opção inicial proposta, isto é, definir o quadro ocupacional atual do enfermeiro não é apenas urgente como também imprescindível para qualquer tomada de posição em relação ao tempo de estágio.

\section{SUGESTÕES PARA DURAÇÃO DOS CAMPOS DE ESTÁGIO}

A Escola de Enfermagem da Universidade Federal da Bahia tem como objetivo formar enfermeiros com os conhecimentos gerais de enfermagem, proporcionando-lhes condições para planejar, executar e supervisionar a assistência de enfermagem.

Conforme as exigências atuais de carga horária para os cursos de enfermagem no País, o estudante deverá cumprir um total de 2.500 horas, para a graduação do Enfermeiro, incluindo o ciclo pré-profissional e o tronco profissional comum. Após a graduação poderá ser feita a opção para as habilitações em Enfermeiro Médico-Cirúrgico, Enfermeira Obstétrica ou Obstetriz e Enfermeiro de Saúde Pública, com uma carga horária de mais 500 horas.

Apesar da existência das habilitações supra citadas, devemos planejar o currículo do ciclo pré-profissional e do tronco profissional comum de forma a capacitar o futuro enfermeiro a exercer a profissão em qualquer dos ramos da enfermagem, pois, de acordo com o levantamento citado, ficou evidenciado que nem sempre o profissional trabalha no seu ramo de habilitação.

$O$ ano acadêmico da Universidade Federal da Bahia compreende dois períodos ou semestres letivos com um mínimo de noventa dias úteis cada um, ou sejam, quinze semanas por semestre.

A medida básica do trabalho escolar é feita pelo sistema de créditos, havendo diferença entre crédito aula e crédito trabalho. Um crédito aula corresponde a quinze horas de teoria ou trinta (30) horas de prática; um (1) crédito trabalho corresponde a quarenta e cinco (45) horas de estágio supervisionado. O estudante poderá escolher as disciplinas de um semestre, perfazendo o mínimo de oito e o máximo de 24 créditos. A escolha das disciplinas depende do número de vagas, dos pré-requisitos (conhecimento adquerido para o estudo da disciplina) e da compatibilização dos horários.

Os cursos de graduação compreendem dois ciclos de estudo: o primeiro e o segundo ciclo. O 1.० Ciclo é constituído de disciplinas nucleares e complementares.

Disciplinas nucleares são aquelas obrigatórias comuns a determinada área: no caso Biologia e Complementos de Química (área da saúde). 
WOLFOVITCH, C., e colaboradores - Experiência de campo necessária à formação do(a) enfermeiro(a). Rev. Bras. Enf., Rio de Janeiro, 28 : 26-55, 1975.

Disciplinas complementares têm como finalidade, complementar a formação necessária para graduação do estudante. Dentre essas disciplinas distinguem-se as de caráter obrigatório e as optativas.

Essas disciplinas contribuem para a formação básica necessária ao $2 .^{\circ}$ Ciclo e proporcionam elementos de cultura geral (disciplina eletiva).

Para a distribuição da carga horária foram necessários alguns indicadores ou mesmo pontos de referência que orientassem sobre que disciplina ou disciplinas deveriam recair maior carga horária; por outro lado essas indicações eram insuficientes, sem critérios que as fundamentassem. Recorremos, por isso, a duas fontes interdependentes: uma análise diagnóstica da situação funcio- nal do enfermeiro em Salvador e um estudo retrospectivo do currículo da Escola de Enfermagem em 10 anos consecutivos. O estudo revelou que a média das atividades exercidas pelos enfermeiros não lhe são específicas e que a ênfase dada à Administração em enfermagem como atividade principal, reduzse quase que exclusivamente a procedimentos rotineiros e de significância profissional discutível. O currículo será analisado detidamente nesta seção. As sugestões aqui emitidas levam em conta esses elementos, mas não os consideram exclusivos, nem definitivos; seu mérito é o de alicerçar em dados científicos.

As disciplinas de estágio aparecem no quadro abaixo com as respectivas médias globais de carga horária, em 10 anos.

Q U A D R O N. N $^{1}$

DISCIṔliNAS, CARGA HORÁRIA, MÉdiA E GRÁU DE APROVEITAMENTO 1960-1970 Escola de Enfermagem da UFBa. - 1972

\begin{tabular}{|c|c|c|c|c|c|c|}
\hline \multirow{3}{*}{ DISCIPLINAS } & \multicolumn{6}{|c|}{ Carga Horária e Médias - 1960/1970 } \\
\hline & \multicolumn{2}{|c|}{ Teoria } & \multicolumn{2}{|c|}{ Estágio } & \multirow{2}{*}{$\begin{array}{c}\text { Teoria } \\
\text { sobre } \\
\text { Estágio } \\
\%\end{array}$} & \multirow{2}{*}{$\begin{array}{l}\text { Média } \\
\text { Globa] }\end{array}$} \\
\hline & N. ${ }^{\circ}$ & $\%$ & N. ${ }^{\circ}$ & $\%$ & & \\
\hline Fundamentos de Enfermagem & 77 & 12,5 & 124 & 8,9 & 62,1 & $\mathbf{M}$ \\
\hline Enfermagem Médica & 133 & 21,7 & 246 & 17,5 & 54,1 & $\mathbf{M}$ \\
\hline Enfermagem Cirúrgica & 138 & 22,5 & 221 & 15,8 & 62,4 & $\mathbf{M}$ \\
\hline Enfermagem Psiquiátrica & 55 & 8,9 & 82 & 5,9 & 67,1 & $\mathbf{M}^{*}$ \\
\hline Enfermagem Obstétrica I & 60 & 9,8 & 147 & 10,5 & 40,8 & MS* \\
\hline Enfermagem de S. Pública I & 22 & 3,6 & 99 & 7,1 & 22,2 & - \\
\hline Enfermagem Pediátrica I & 50 & 8,1 & 130 & 9,3 & 38,5 & MS \\
\hline Enfermagem de S. Pública II & 22 & 3,6 & 99 & 7,1 & 22,2 & $\mathbf{M}$ \\
\hline Adm. em Serv. de Enfermagem & 33 & 5,4 & 189 & 13,5 & 17,5 & MS \\
\hline Sup. e Treinamento & - & - & - & - & - & - \\
\hline Emergência & 24 & 3,9 & 62 & 4,4 & 38,7 & 一 \\
\hline TOTAL & 614 & 100,0 & 1399 & 100,0 & 43,9 & \\
\hline
\end{tabular}

FONTE: - Arquivo da EEUFBa.

O sistema de avaliacão anterior a 1970 foi readaptado ao atual sistema de conceitos, com seus respectivos símbolos e valores: $\mathbf{M}$ - médito (três), MS - médio superior (quatro). 
WOLFOVITCH, C., e colaboradores - Experiência de campo necessária à formação do(a) enfermeiro(a). Rev. Bras. Enf., Rio de Janeiro, 28 : 26-55, 1975.

Analisando a distribuição da teoria observa-se que as disciplinas Enfermagem Cirúrgica e Enfermagem Médica são as que aparecem com maior percentual sobre o total da carga horária, com uma diferença de quase $50 \%$ para a disciplina seguinte, Fundamentos de Enfermagem. As demais variam entre $9,8 \%$ e $3,6 \%$. Quanto aos estágios a situação é semelhante em termos de variação, mas as incidenciais não recaem necessariamente sobre as mesmas disciplinas, embora guardem alguma relação. A incidência da teoria sobre a prática deveria manter-se em torno de um percentual admitido como aceitável. Entretanto, essa incidência varia de $13,5 \%$ para Enfermagem Psiquiátrica 5,9\% em Administração em Serviço de Enfermagem. Significa que Enfermagem Psiquiátrica, no período estudado, teve a menor carga horária em estágio e Administração em Serviço de Enfermagem a maior.

A análise dos 10 anos de currículo evidencia variações bastante significativas entre disciplinas com aparente igualdade de significação para a formação profissional; todavia, as justificati- vas ou mesmo os fundamentos parecem residir nos objetivos programáticos de cada professor, não completamente enquadrados nos objetivos finalísticos a que se destina o curso. Convém salientar que o periodo analisado é anterior à reforma, onde, de fato, a ausência de órgãos colegiados responsáveis pela programação dos cursos atribuída ao professor, arbitrio para agir independente de qualquer ponto de referência que orientasse sua ação. Evidencia-se, por outro lado, que embora tenham havido variaçōes consideráveis tanto na carga horária como no número de disciplinas, o tronco básico das profissionalizantes mantevese praticamente inalterado durante os 10 anos considerados. Se existe de fato, relação entre disciplinas profissionalizantes e eficiência na ação prática, o currículo precisaria ser revisto não à luz de conceitos ideais da profissão, mas à luz das atividades efetivamente desempenhadas pelos enfermeiros. este 0 motivo que nos levou a fazer um diagnóstico de situação funcional do enfermeiro em Salvador. 


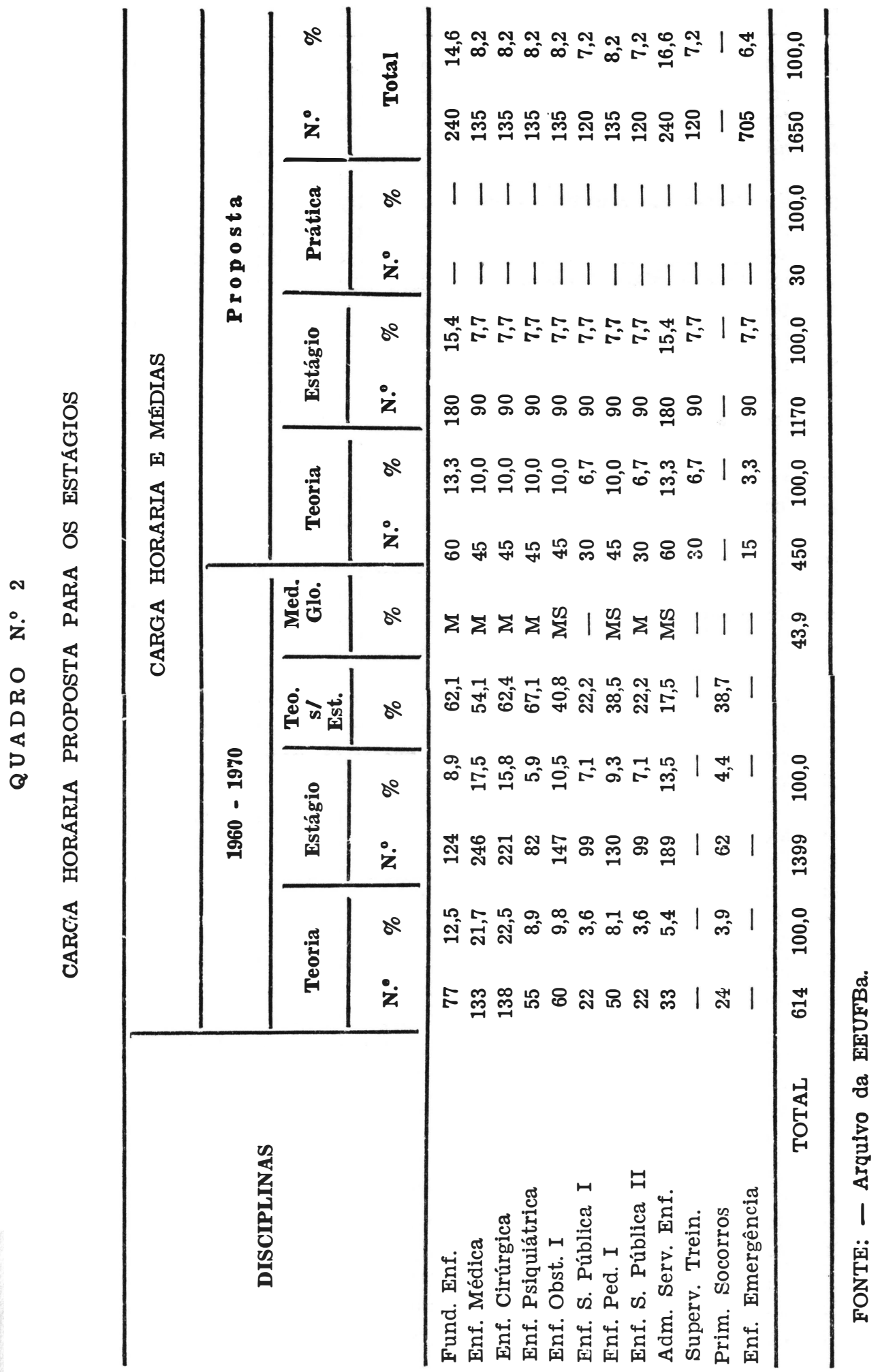


WOLFOVITCH, C., e colaboradores - Experiência de campo necessária à formação do(a) enfermeiro(a). Rev. Bras. Enf., Rio de Janeiro, 28 : 26-55, 1975.

A partir do $3 .^{\circ}$ semestre o estudante inicia o curso profissionalizante que se desenvolve com o predomínio das atividades práticas, isto é, a maioria das disciplinas deste ciclo exige preparo de campo. Em enfermagem a prática é de grande importância no processo educacional, porém o desenvolvimento do raciocínio é fundamental para que o estudante adquira a capacidade de adaptação a situações novas. O objetivo do ensino é estimular a capacidade de raciocínio orientado no sentido da aplicação dos princípios científicos à prática.

Até há pouco tempo havia uma preocupação dos professores de Enfermagem para que o estudante cumprisse uma escala de serviço, enraigados que estavam no tradicionalismo do ensino, quando se enfatizava a duração dos estágios.

Hoje, os professores, refletindo sobre os problemas educacionais, não consideram apenas o tempo de permanência no campo como fator primordial para 0 aprendizado. Entretanto, se o fator tempo não é o principal para o aprendizado de algumas disciplinas, é importante para outras. $\mathrm{t}$ o caso da disciplina Introdução à Enfermagem, cujo objetivo principal é o desenvolvimento de habilidades através do cuidado integral ao paciente, necessitando maior treinamento e por conseguinte um tempo mais prolongado.

O preparo básico é importante e deve ser considerado na distribuição da carga horária. Esse preparo, os estudantes estão recebendo no $1^{\circ}$ ciclo, e estão alcançando o curso profisisonalizante com um conjunto de conhecimentos que serão utilizados na prática, de acordo com as necessidades.

Também é fator importante para o aprendizado o preparo de campo. Um campo bem preparado oferece condiçōes para que o estudante aproveite bem as horas que lhes são oferecidas para estágio, permitindo-lhe desenvolver as suas potencialidades. Os professores: fazendo dos hospitais universitários os seus laboratórios de trabalho, podem: preparar o campo conveniente para melhor aproveitamento do estudante. Além disso, é também importante os professores servirem de modelos para os estudantes, que aprendem pelo exemplo do trabalho do professor. Nos hospitais universitários os campos preparn.

pelos professores devem ser planejados, tendo em vista os seguintes pontos:

1 - Conhecimento da especialidade que o professor se propõe a ensinar.

2 - Integração efetiva entre as escolas de enfermagem e hospitais que servem de campo de estágio para os alunos.

3 - Serviços com número de pacientes que proporcione condições para que o professor possa associar a chefia, assistência e a pesquisa.

Após o desenvolvimento de habilidades e a conceituação do cuidado integral aos pacientes; ensinamentos adquiridos na disciplina Introdução à Enfermagem, o estudante deverá ser treinado a trabalhar em equipe aprendendo a distribuir tarefas que podem ser delegadas, selecionando aquelas que devem ser realizadas pelo enfermeiro. Esta filosofia de trabalho é válida não só para preparar o aluno a enfrentar a realidade da profissão, como já foi provado no levantamento, mas, também, evita repetição de ensinamentos que causam falta de motivação aos estudantes. Ademais, com a redução da carga horária nas diversas disciplinas de estágio, as horas deverão ser mais utilizadas nos aspectos epecíficos da disciplina. 
WOLFOVITCH, C., e colaboradores - Experiência de campo necessária à formação do(a) enfermeiro(a). Rev. Bras. Enf., Rio de Janeiro, 28 : 26-55, 1975.

O estudante deve ser treinado para trabalhar dentro da realidade da comunidade, porque muitas vezes os hospitais-escola não retratam a situação real dos serviços de enfermagem das comunidades brasileiras. Muitos estudiosos recomendam que não se usem como campo de estágio somente estes hospitais, mas que se estenda o treinamento para outros, facilitando, desse modo, a integração Universidade-Comunidade.
O tipo de currículo existente até o momento pode ser considerado como um dos fatores influentes no desvio das atividades. Com base nesta hipótese, pen. sou-se em corrigir esse desvio enfatizando-se as disciplinas que supõe-se servirem de base mais diretamente à atuação prática e que figuram no Quadro 3.

QUADRO N.० 3

CARGa horaria proposta para os estágios

\begin{tabular}{|c|c|c|c|c|c|c|c|c|}
\hline \multirow{2}{*}{ DISCIPLINAS } & \multicolumn{2}{|c|}{ Teoria } & \multicolumn{2}{|c|}{ Estágio } & \multicolumn{2}{|c|}{ Prática } & \multicolumn{2}{|c|}{ Total } \\
\hline & N.o & $\%$ & N.o & $\%$ & N.o & $\%$ & N.o & $\%$ \\
\hline Introd. à Enfermagem & 60 & 13,3 & 180 & 15,4 & 30 & 100,0 & 270 & 16,4 \\
\hline Enf. Médica I & 45 & 10,0 & 90 & 7,7 & - & - & 135 & 8,2 \\
\hline Enf. Cirúrgica I & 45 & 10,0 & 90 & 7,7 & - & - & 135 & 8,2 \\
\hline Enf. Psiquiátrica & 45 & 10,0 & 90 & 7,7 & - & - & 135 & 8,2 \\
\hline Enf. D. Transmissíveis & 45 & 10,0 & 90 & 7,7 & - & - & 135 & 8,2 \\
\hline Enf. S. Pública I & 30 & 6,7 & 90 & 7,7 & - & - & 120 & 7,2 \\
\hline Enf. Pediátrica I & 45 & 10,0 & 90 & 7,7 & - & - & 135 & 8,2 \\
\hline Enf. S. Pública II & 30 & 6,7 & 90 & 7,7 & - & - & 120 & 7,2 \\
\hline Adm. Serv. Enf. & 60 & 13,3 & 180 & 15,4 & 一 & - & 240 & 14,6 \\
\hline Superv. Trein. & 30 & 6,7 & 90 & 7,7 & 一 & - & 120 & 7,2 \\
\hline Enf. Emergência & 15 & $:$ & 90 & 7,7 & - & - & 105 & 6,4 \\
\hline TOTAL & 450 & 100,0 & 1170 & 100,0 & 30 & 100,0 & 1650 & 100,0 \\
\hline
\end{tabular}

FONTE: - Arquivo da EEUFBa.

Como pode ser visto, a disciplina $\mathrm{Su}$ pervisão e Treinamento de Pessoal de Enfermagem, introduzida há um ano nesta Escola, será conservada, visto que o levantamento mostra a sua necessidade.

Note-se que a disciplina Introdução à Enfermagem ficou com uma carga horária de $\mathbf{2 7 0}$ horas. Usou-se como critério para estabelecer esta carga a necessidade de exercitar as técnicas para adquirir habilidade, o que exige mais tempo de treinamento em campo.

Nesta fase o aluno adquire destreza, 
WOLFOVITCH, C., e colaboradores - Experiência de campo necessária à formação do(a) enfermeiro(a). Rev. Bras. Enf., Rio de Janeiro, $28: 26-55,1975$.

e é orientado a reconhecer as necessidades individuais do paciente - primeira etapa do planejamento - uma vez que ainda não estão com a formação clínica para planejar a assistência na sua totalidade. Como, para o desenvolvimento da habilidade técnica, admite-se que a repetição é importante e esta repetição implica em tempo, este estágio teve uma concentração maior de carga horária.

Outro critério para a fixação dessa carga horária é ser uma disciplina básica para as subsequentes, pois, é nesta oportunidade que o aluno aprende a fundamentação dos princípios que regem a enfermagem. A prática nos tem mostrado que nos estágios de Enfermagem Médico-Cirúrgica os alunos ainda têm insegurança no desenvolvimento de técnica dispendendo uma grande parte do tempo em treinamento da habilidade, não podendo aproveitar o tempo do estágio para o preparo específico.

Previmos para Enfermagem Médica I, Cirúrgica, Psiquiátrica, Obstétrica I, Pediátrica I e em Doenças Transmissíveis, a carga horária de 135 horas para cada uma, pois, havendo preparo adequado em Introdução à Enfermagem, o tempo utilizado em estágio será aproveitado para o ensino específico da especialidade a que se propõe o curso.

Apesar de Enfermagem Médica e Cirúrgica constituírem disciplinas básicas não estão com uma carga horária condizente. Pode ser justificada porque os aspectos médico-cirúrgicos são vistos durante os demais estágios onde os alunos ampliarão seus conhecimentos.

Os programas destas disciplinas deverão constar de assuntos básicos indispensáveis à formação geral do enfermeiro, selecionando-se os assuntos mais especiais para o semestre de Habilitação.

Considerando-se Doenças Transmissíveis como problemas de Saúde Pública, procurou-se integrar Enfermagem de Doenças Transmissíveis à Enfermagem de Saúde Pública, dando-se o aspecto global do problema. Os estudantes farão estágios em Centros de Saúde e Clínicas de Doenças Transmissíveis.

De acordo com os dados obtidos no levantamento das atividades dos enfermeiros em Salvador foi constatado que a grande maioria exerce a atividade de Supervisão de Pessoal Auxiliar. Sentimos a necessidade de manter esta disciplina que está sendo ministrada há um ano e enfatizar a sua necessidade com uma carga horária de 120 horas.

Como foi apresentado no início do capítulo, foram mantidas as disciplinas necessárias à formação do enfermeiro, embora algumas com uma carga horária menor, como são os casos de Enfermagem de Saúde Pública I, cujos conhecimentos serão complementados com o curso de habilitação e Enfermagem de Emergência que não poderia deixar de ser dada no curso de graduação. Para estas duas disciplinas reservamos uma carga horária de 120 horas e 105 horas respectivamente.

No que diz respeito à Administração aplicada à Enfermagem, considerando ainda os resultados do levantamento sobre as funções dos enfermeiros, nós nele nos fundamentamos para propor a manutenção da carga de 180 horas, satisfazendo assim uma necessidade verificada e comprovada, visto que a maioria dos enfermeiros exercem funções de chefia de Serviços ou Unidades de Enfermagem.

Por outro lado, sabendo que as atividades administrativas dos enfermeiros chefes não estão na sua maioria condízendo com os objetivos prupostos, poderia parecer um contra-senso atribuir à disciplina a carga horária cie 180 horas; entretanto, achou-se justificável, pelo fato de que tem-se que formar ain- 
WOLFOVITCH, C., e colaboradores - Experiência de campo necessária à formaçăo do(a) enfermeiro(a). Rev. Bras. Enf., Rio de Janeiro, $28: 26-55,1975$.

da por algum tempo enfermeiros para exercer cargos de chefia.

Por esse motivo é importante orientar os cursos, de modo a que a administração aplicada à enfermagem seja dirigida no sentido de administrar a equipe de enfermagem, provendo a satisfação das necessidades do paciente, implicando isso na assistência direta ao mesmo por parte do enfermeiro chefe.

O curso de Habilitação é destinado à formação específica, de acordo com a escolha de cada estudante. As disciplinas devem ser ministradas de maneira a que os estudantes possam ter responsabilidades e atribuições semelhantes àquelas exercidas na vida prática, isto é, regime de trabalho, responsabilidades e atribuiçōes nos quais se procuram integrar os aspectos administrativos à assistência do paciente. oportunidade do estudante adquirir segurança perdendo aquele temor inicial que é comum no enfermeiro no início do exercício profissional.

Não nos preocupamos em apresentar a distribuição das disciplinas na carga horária de $\mathbf{5 0 0}$ horas conforme determinação, porque achamos que não há dificuldade em fazê-lo.

No Anexo XI apresentamos uma sugestão de currículo com a distribuição de todas as disciplinas nos semestres e respectiva carga horária.

\section{CONCLUSŌES}

1. O presente trabalho procurou identificar as funçōes exercidas pelos enfermeiros de Salvador, os resultados constituíram subsídio para a atribuição da carga horária nos diversos estágios e disciplinas.

2. Existe "déficit" de enfermeiros ocupando cargos de assistência; a grande maioria está exercendo o cargo de chefes de Unidades e Serviços de Enfermagem.

3. As atividades verbalizadas pelos enfermeiros nos diversos campos de trabalho não correspondem àquelas que admitimos serem especificas do enfermeiro, constatando-se sobrecarga de atividades burocráticas.

4. As atividades do enfermeiro de Saúde Pública são as que mais se aproximam daquelas específicas do enfermeiro, o que não foi verificado na área hospitalar.

5. Não está havendo preparo especifico dos enfermeiros para exercício dos cargos que ocupam. Dentre os enfermeiros pesquisados, $84,6 \%$ não possuem preparo além do curso de graduação e já no primeiro emprego exercem, na sua maioria, cargos de chefia, portanto nāo existe critério para ocupação de cargos de chefia relacionados com experiências anteriores.

6. Nāo foram encontrados na equipe de enfermagem profissionais encarregados da execução de tarefas burocráticas deduzindo-se daí ser uma das causas que concorre para o desvio de atividades.

7. Das tarefas verbalizadas pelos enfermeiros foi uma constante a supervisão de pessoal de enfermagem; por este motivo fol conservada a disciplina Supervisão e Treinamento de pessoal de Enfermagem que já vem sendo ministrada nesta Escola há um ano.

8. O curso de enfermagem para graduação do enfermeiro foi orientado no sentido de dar uma formação básica que o prepare para enfrentar a vida profissonal em qualquer dos ramos da enfermagem. 
WOLFOVITCH, C. e colaboradores - Experiência de campo necessário à formação do(a) enfermeiro(a). Rev. Bras. Enf., Rio de Janeiro $28: 26-55,1975$.

9. Na maioria dos estágios, a duração não é condição principal para o bom aproveitamento. Preparo de campo e o exemplo, do trabalho do professor são também condições fundamentais para o aprendizado e influem na distribuição da carga horária.

10. A disciplina Introdução à Enfermagem teve a maior concentração de carga horária porque alérn de fundamentar as demais, o aluno necessita adquirir destreza nas técnicas.

11. Um dos fatores que influe na distribuição da carga horária é a metodologia do ensino.

12. A disciplina Administração apli- cada à Enfermagem obteve uma carga horária maior em relação as demais para satisfazer uma necessidade verificada e comprovada, visto que a maioria dos enfermeiros logo após a graduação vai exercer cargo de chefia.

14. Foi atribuída menor carga horária às disciplinas: Enfermagem Médica I, Enfermagem Cirúrgica I, Enfermagem Pediátrica I, Enfermagem Obstétrica I, Enfermagem de Doenças Transmissíveis, Enfermagem de Saúde Pública I, porque havendo uma boa base no curso de Introdução à Enfermagem o tempo do estágio será aproveitado para os aspectos específicos, como também posteriormente estes conhecimentos serão consolidados nos cursos de habilitação respectivos.

\section{BIBLIOGRAFIA}

AMSDEN, A. L. - What the nurses didand are doing. Nurs. Times 67: 672-3, jun. 3, 1971.

BAUGH, E. L. - Nursing education opportunities. Nurs. Outlook 20: 100-2, feb. 1972.

DUTRA, V. O. - Preparo em serviço para integração do recém-graduado na vida profissional. R. Bras. Enf. 23: 75-71, jul-dez. 1970.

GODOY, A. N. - O sistema de internato como estágio de administração aplicada à enfermagem. R. Bras. Enf. 20: 31-5, jan-fev. 1967.

GONZALEZ. E. \& OLIVEIRA, M. I. R. Programa de livros de textos para estudantes de cursos básicos de enfermeira; Documento básico. Washington, OPS/OMS, s.d.

GRAVES, H. H. - Can nursing shed burcaucracy? Amer. J. Nurs. 71: 490-4, apr. 1971.

INGRES, T. \& MONTAG, M. - Debate: Ladder consep in nursing education. Nurs Outlook. 19: 726-30, nov. 1971.

JOHNSON, W. L. - Status of the open curriculum in nursing. Nurs Outlook. 19: 779-82, dec. 1971.
KELLER, N. S. - Head nurse and clinical teacher. Nurs. Outlook. 19: $55^{\circ} 0-9$, set. 1971.

KRAMER, M. - Team nursing - a means or an end? Nurs. Outlook 19: 648-52,

LONGWAY, I. M. - Curriculum concept historical analysis. Nurs. Outlook 20: 116-20, feb. 1972.

MCCAFFERY, M. - What is the student learning in the clinical laboratory? J. Nurs. Educ. 7: 3-10, nov. 1968.

PAYNICH, M. L. - Why do basic nursing students Work in nursing? Nurs Outlook. 19: 242-5, apr. 1971.

ROY, C. - Adaptation: a basis for nursing practice. Nurs. Outlook. 19: 254-7, apr. 1971.

SANTOS, C. F. \& MINZONI, M. A. - Estudo das atividades de enfermagem em quatro unidades de um hospital governamental. R. Bras. Enf. 21: 396441. out. 1968.

UNIVERSIDADE FEDERAL DA BAHIA CATALOGO GERAL 1972 


\section{ANEXO I}

\section{EXPERIÊNCIA DE CAMPO NECESSÁRIA À FORMAC̣ÃO DA(O) ENFERMEIRA(0)}

I - INSTITUIÇÃO

1. Hospital

2. Secretaria de Saúde

3. Centro de Saúde

4. Posto de Saúde

5. Dispensário

6. Ambulatório

7. Escola de Puericultura

8. Escola de Enfermagem

9. Escola de Auxiliar de Enfermagem

II - ENTIDADE MANTENEDORA

1. Governamental

2. Particular

3. Fundação

4. Outras (especificar)

III - TIPO DE HOSPITAL
1. Geral
2. Especializado
3. Não trabalha em hospital

IV - CARGO OU FUNÇÃO QUE EXERCE

1. Chefia de Serviço

2. Chefia de Setor

3. Chefia de Unidade de Enfermagem

4. Assistência

5. Ensino

6. Pesquisa

7. Outras (especificar)

V - Solicitar a descrição da ocupação, enfatizando as tarefas básicas. 
1. De 01 a menos de 10

2. De $10 " \quad " 20$

3. De $20 " \quad " 30$

4. De $30 " \quad " 40$

5. De $40 " " \quad 50$

6. De $50 " \quad " 100$

7. 100 e mais

8. Nenhum

VII - N..$^{\circ}$ DE PESSOAS SOB SUA RESPONSABILIADE

(A enfermeira que só exerce função de assistência, não responde esta pergunta).

1. Enfermeira

N. ${ }^{\circ}$

Observação

2. Auxiliar de Enfermagem

3. Atendente

4. Secretária de Unidade

5. Visitadora Sanitária

6. Servente

7. Outros (especificar)

8. Nenhum

VIII - ANO DE GRADUAÇAO

IX - AREA DE GRADUAÇÃO

1. Enfermagem

2. Enfermagem Obstétrica

3. Enfermagem de Saúde Pública

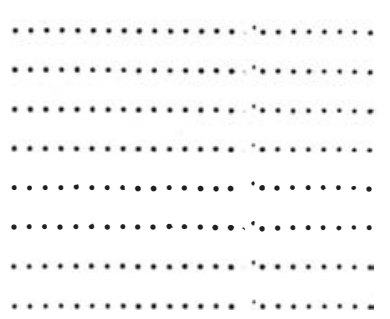

X - TEMPO QUE EXERCE O CARGO OU FUNÇAO.

1. Menos de 1 ano

2. De 1 a menos de 5 anos

3. De 5 a menos de 10 anos

4. De 10 a menos de 15 anos

5. De $15 "$ " 20 anos

6. 20 e mais

XI - CARGO OU FUNÇAO EXERCIDOS ANTERIORMENTE

1. Chefia de Serviço

2. Chefia de Setor

3. Chefia de Unidade de Enfermagem

4. Assistência

5. Ensino

6. Pesquisa

7. Outros (especificar)

8. Não exerceu cargos anteriores

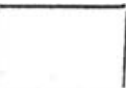


XII - CURSOS:

1. Pós-graduação

1. Sim

2. Não

2. Especialização

1. Sim

2. Não

Em caso positivo, identificar separadamente.

XIII - REGIME DE TRABALHO (horas semanais)

1. 12 horas

2. 24 horas

3. $30 "$

4. $33 "$

5. $40 "$

6. Outros (especificar)

XIV - TEVE PREPARO ESPECFFICO PARA O CARGO OU FUNÇÃO QUE EXERCE?

1. Sim

2. Não

Em caso positivo, qual e onde?

XV - QUAIS AS DIFICULDADES QUE TEVE NO INICIO DO EXERCICIO PROFISSIONAL?

XVI - PARA INICIAR A VIDA PROFISSIONAL, O CURRICULO DO CURSO DE GRADUAÇAO FOI:

1. Suficente

2. Insuficiente

Por que?

XVII - ESTÁ SATISFEITA COM A ATIVIDADE QUE EXERCE?

1. $\operatorname{Sim}$

2. Não

Por que?

Em caso negativo, que tipo de atividade gostaria de exercer? 


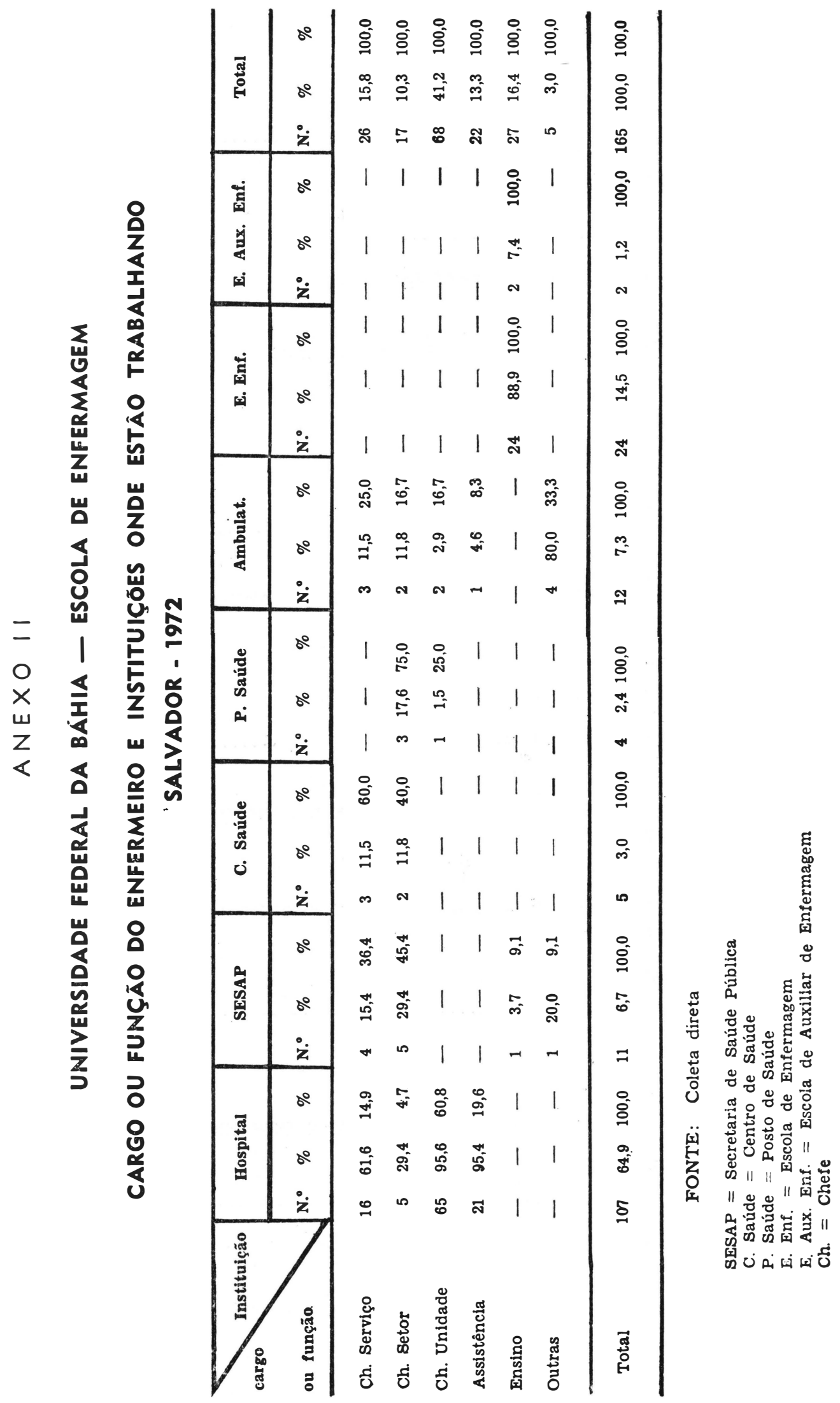




\section{A NEXO I I I \\ DESCRIÇÃO DA OCUPAÇÃO DOS ENFERMEIROS}

\section{CHEFIA DE SERVIÇO:}

Supervisão das atividades de enfermagem. Escalas de serviço. Coordenenação de enfermagem. Controle de material. Educação em Serviço. Distribuição de pessoal nos diversos setores. Censo diário. Cuidado direto ao paciente. Abastecimento da farmácia. Passagem de plantão. Controle de exames dos pacientes. Transcrição de ordens médicas. Controle de medicação. Pedido de consertos. Preparo de rotinas. Alta do paciente. Supervisão da limpeza. Reunião com pessoal de enfermagem.

\section{CHEFIA DE SETOR:}

(Saúde Pública)

Educação em serviço. Cuidado direto ao paciente. Orientação e supervisão de estudantes. Supervisão das atividades de enfermagem. Escala do pessoal de Enfermagem. Pedido de material. Pedido de medicação. Supervisão de imunização. Encaminhamento de guias de exame de laboratório. Relatório estatístico diário. Aplicação de medicação especializada. Execução do plano médico. Reuniões com o pessoal de enfermagem. Entrevista com pacientes. Distribuição de serviço. Seleção de pacientes para consultas. Encaminhamento de pacientes. Consulta de enfermeiro.

\section{CHEFIA DE UNIDADE DE ENFERMAGEM \\ (Hospitalar)}

Supervisão do pessoal de enfermagem. Transcrição de ordens médicas. Cuidado direto ao paciente. Controle de material. Pedido de medicamentos. Escalas de ser- viço. Pedido de material. Edu.cação em serviço. Visita aos paciente. Supervisão de limpeza. Controle de medicamentos. Edu.cação sanitária. Distribuição de serviço. Acompanhamento à visita médica. Atividades administrativas. Requisição para consertos. Supervisão de estudantes de enfermagem. Reuniões com pessoal auxiliar. Controle de tóxicos. Passagem de plantão. Estatística das atividades de enfermagem. Plano de cuidados. Revisão dos prontuários. Censo diário. Imunização. Cooperação com a equipe médica. Entrosamento com os diversos serviços. Colabora com o ensino ministrando aulas teóricas. Reuniões com o corpo clínico. Montagem da sala de operação. Pedidos de consulta. Elaboração de relatórios para os departamentos do hospital. Providência de exames fora da instituição. Admissão do paciente na unidade. Encaminhamento de exames Freqüência do pessoal auxiliar. Praxiterapia.

\section{ASSISTENCIA :}

Cuidado direto ao paciente. Supervisão do pessoal de enfermagem. Transcrição de ordens médicas. Visita aos pacientes. Pedido de medicação. Pedido de material. Supervisão de limpeza. Passagem de plantão. Revisão de prontuários. Distribuição de serviço. Controle de medicação. Escala de serviço. Educação em serviço. Controle de material. Admissão do paciente. Peso. Plano de cuidado. Plano de alta. Censo diário. Acompanhamento à visita médica. Reuniões mensais. Relatório de atendimento médico. Encaminhamento ao Serviço Social. Coordenação da vigilância e barbearia. 


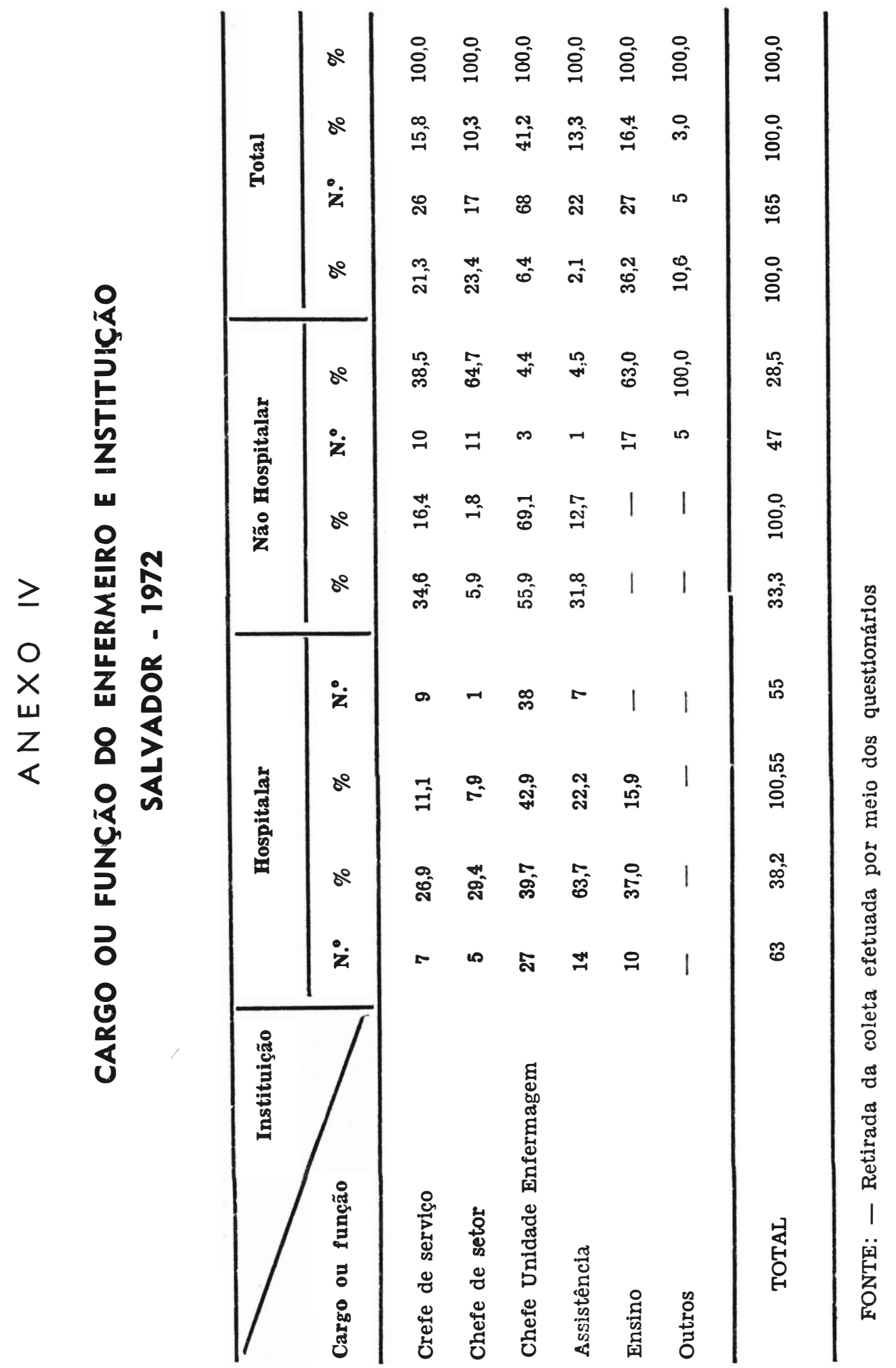




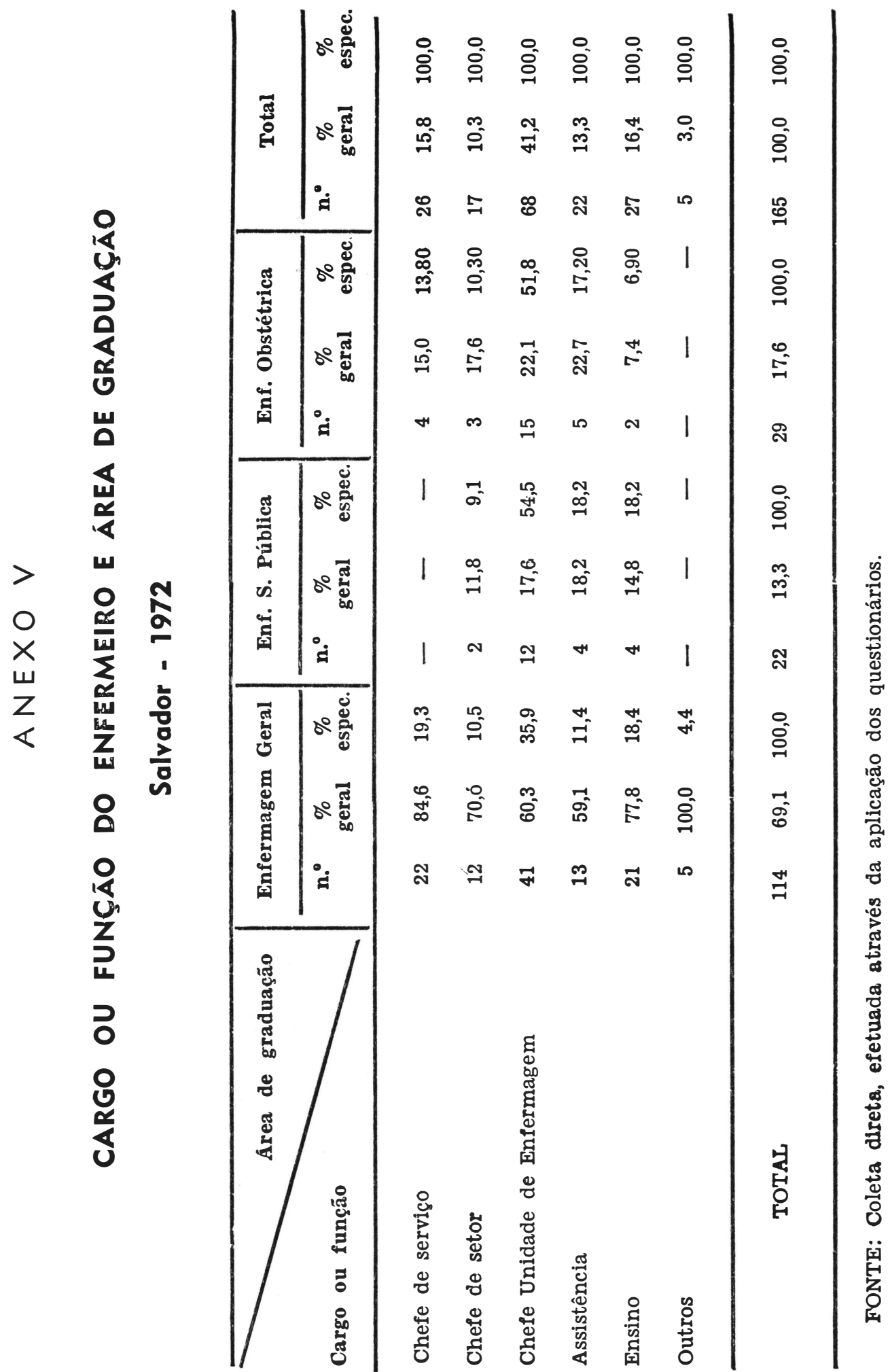




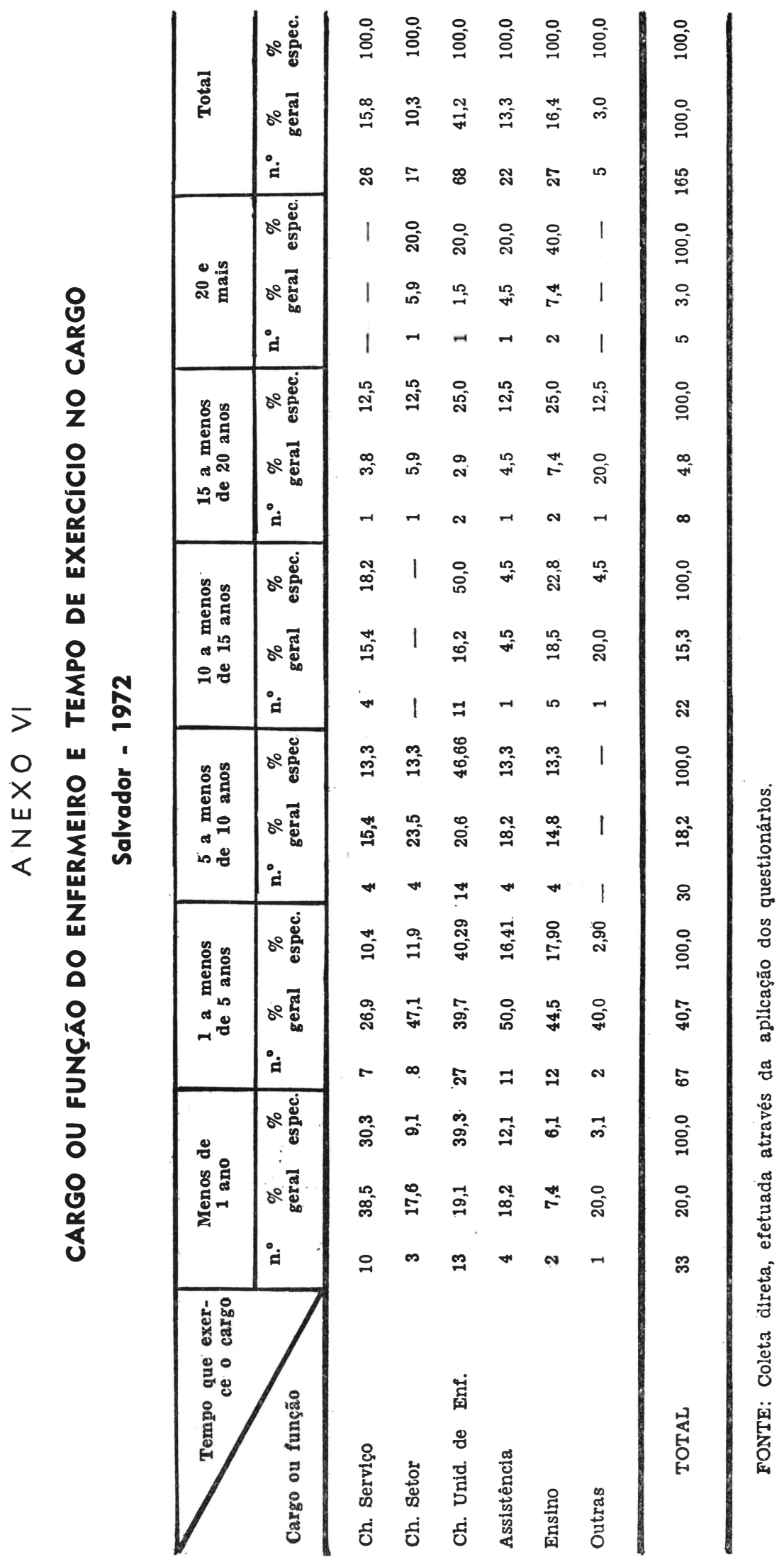




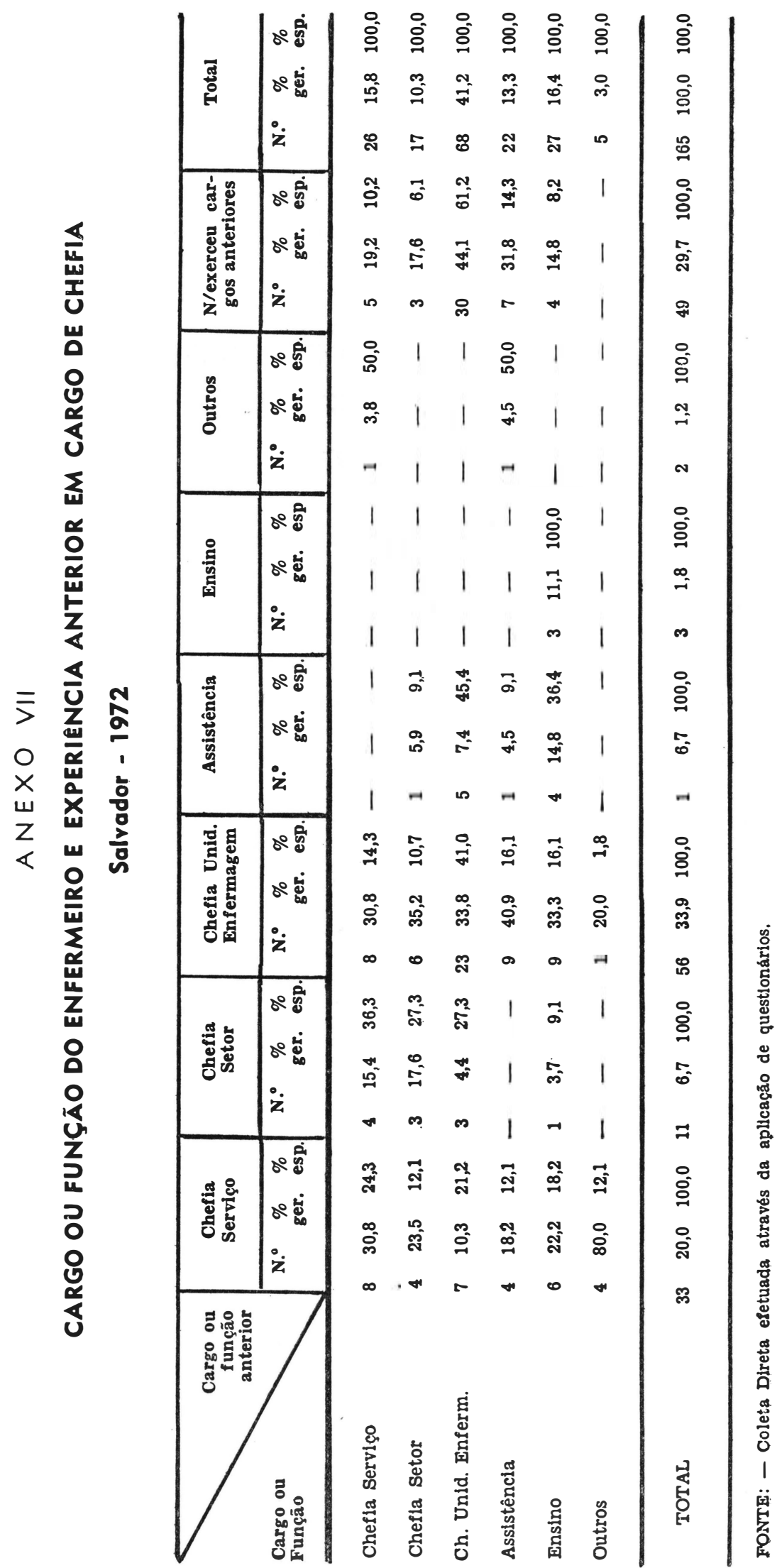




\section{ANEXO VIII \\ CARGO OU FUNÇÃO DO ENFERMEIRO E CURSO DE ESPECIALIZAÇÃO \\ Salvador - 1972}

\begin{tabular}{|c|c|c|c|c|c|c|c|c|c|}
\hline \multirow{2}{*}{$\begin{array}{l}\text { Cargo ou } \\
\text { função }\end{array}$} & \multicolumn{3}{|c|}{ SIM } & \multicolumn{3}{|c|}{ NÃO } & \multicolumn{3}{|c|}{ TOTAL } \\
\hline & $\mathbf{N}$. & $\%$ & $\%$ & N.o & $\%$ & $\%$ & N.o & $\%$ & $\%$ \\
\hline Ch. Serviço & 4 & 15,4 & 7,5 & 22 & 84,6 & 19,6 & 26 & 15,8 & 100,0 \\
\hline Ch. Setor & 6 & 35,3 & 11,3 & 11 & 64,7 & 9,8 & 17 & 10,3 & 100,0 \\
\hline Ch. Unid. Enf. & 23 & 33,8 & 43,5 & 45 & 66,2 & 40,2 & 68 & 41,2 & 100,0 \\
\hline Assistência & 11 & 50,0 & 20,7 & 11 & 50,0 & 9,8 & 22 & 13,3 & 100,0 \\
\hline Ensino & 9 & 33,3 & 17,0 & 18 & 67,7 & 16,1 & 27 & 16,4 & 100,0 \\
\hline Outros & 一 & - & - & 5 & 100,0 & 4,5 & 5 & 3,0 & 100,0 \\
\hline TOTAL & 53 & 32,1 & 100,0 & 112 & 67,9 & 100,0 & 165 & 100,0 & 100,0 \\
\hline
\end{tabular}

FONTE. - Coleta direta aplicada através de aplicação de questionário. 


\section{ANEXO IX}

\section{SUGESTÃO PARA DISTRIBUIÇÃO DAS DISCIPLINAS POR SEMESTRE}

\section{1. ${ }^{\circ}$ SEMESTRE}

\begin{tabular}{|c|c|c|c|c|c|c|c|c|c|}
\hline \multirow{3}{*}{ DISCIPLINAS } & \multicolumn{4}{|c|}{$\begin{array}{l}\text { Carga horária } \\
\text { semestral }\end{array}$} & \multicolumn{5}{|c|}{ CRÉDITOS } \\
\hline & \multirow{2}{*}{\multicolumn{4}{|c|}{$\begin{array}{l}\text { Aul. Aul. Está- } \\
\text { tećr. prát. gio Total }\end{array}$}} & \multirow{2}{*}{\multicolumn{3}{|c|}{$\frac{\text { Crédito-Aula }}{\text { teór.prát. total }}$}} & \multirow{2}{*}{\multicolumn{2}{|c|}{$\begin{array}{l}\text { Créd. } \\
\text { trab. Total }\end{array}$}} \\
\hline & & & & & & & & & \\
\hline Bioquímica básica & 45 & 30 & - & 75 & 3 & 1 & 4 & - & 4 \\
\hline Anatomia I & 30 & 30 & - & 60 & 2 & 1 & 3 & 一 & 3 \\
\hline Compl. Química I & 60 & - & - & 60 & 4 & 一 & 4 & - & 4 \\
\hline Psicologia I & 60 & 一 & - & 60 & 4 & 一 & 4 & 一 & 4 \\
\hline Saúde e Comunidade & 45 & 一 & 一 & 45 & 3 & 一 & 一 & 3 & 3 \\
\hline Ética & 45 & - & - & 45 & 3 & 一 & 一 & 3 & 3 \\
\hline TOTAL & 285 & 60 & - & 345 & 19 & 2 & 15 & 6 & 21 \\
\hline
\end{tabular}

\section{SEMESTRE}

\begin{tabular}{|c|c|c|c|c|c|c|c|c|c|}
\hline \multirow{2}{*}{ DISCIPLINAS } & \multicolumn{4}{|c|}{$\begin{array}{l}\text { Carga horária } \\
\text { semestral }\end{array}$} & \multicolumn{5}{|c|}{ CRÉDITOS } \\
\hline & \multicolumn{4}{|c|}{$\begin{array}{l}\text { Aul. Aul. Está- } \\
\text { teór. prát. gio Total }\end{array}$} & \multicolumn{3}{|c|}{$\frac{\text { Crédito-Aula }}{\text { teór.prát. total }}$} & \multicolumn{2}{|c|}{$\begin{array}{l}\text { Créd. } \\
\text { trab. Total }\end{array}$} \\
\hline Psicologia II & 45 & - & 一 & 45 & 3 & 一 & 3 & - & 3 \\
\hline Biologia & 60 & - & 一 & 60 & 4 & 一 & 4 & 一 & 4 \\
\hline Fisiologia I & 30 & 30 & - & 60 & 2 & 1 & 3 & 一 & 3 \\
\hline Parasit. Humana I & 30 & 30 & 一 & 60 & 2 & 1 & 3 & 一 & 3 \\
\hline Microbiologia I & 30 & 30 & 一 & 60 & 2 & 1 & 3 & - & 3 \\
\hline Hig. e Saneamento & 45 & - & 一 & 45 & 3 & 一 & 3 & 一 & 3 \\
\hline TOTAL & 240 & 90 & - & 330 & 16 & 3 & 19 & - & 19 \\
\hline
\end{tabular}

